\title{
Chiral Bicyclic Tetramates as Non-Planar Templates for Chemical Library Synthesis
}

\author{
Muhammad Anwar and Mark G. Moloney* \\ Department of Chemistry, Chemistry Research Laboratory, \\ The University of Oxford, 12 Mansfield Road, Oxford, OX1 \\ 3TA, UK \\ ${ }^{\star}$ Corresponding author: Mark G. Moloney, \\ mark.moloney@chem.ox.ac.uk
}

Chemoselective Dieckmann cyclization reactions may be used on oxazolidine and thiazolidine templates derived from various aldehydes to access bicyclic tetramates, which have potential as templates for chemical library construction. Bioassay against Staphylococcus aureus and Escherichia coli showed that these systems have little or no intrinsic antibacterial bioactivity.

Key words: chemical structure, cheminformatics, combinatorial chemistry, drug design

3 Received 12 December 2012, revised $x x-x$ and accepted for publication 15 January 2013

4 We have been working on a programme aimed to develop novel antibacterials modelled on natural products (1), including equisetin (2), reutericyclin (3), kibdelomycin (4) and streptolydigin (5), which all possess a core tetramate unit (6). To this end, we have used our published approach for the synthesis of highly substituted tetramates, which relies upon Dieckmann cyclization of templates 2a,b derived from serine $\mathbf{1 a}$ (7) or threonine $\mathbf{1 b}(8)$. However, this work was limited to the use of pivaldehyde as the condensing species (Scheme 1) (9), which led to very hydrophobic tetramate products $\mathbf{3} \mathbf{a}, \mathbf{b}$. We wished to use polar aldehydes to improve molecular polarity and aqueous solubility, so that the resulting templates were more suitable for drug development, and embarked on a study to expand the scope of this sequence, the results of which are reported here.

We initially chose L-cysteine as the amino acid partner, believing that the resulting $N, S$-acetal systems would be more stable. We found that when L-cysteine methyl ester 4 was reacted with furfural, thiophene aldehyde, $p$-fluorobenzaldehyde, $p$-nitrobenzaldehyde, 2,3,5-trichlorbenzaldehyde and 5-methylisoxazole-3-carbaldehyde using the reported conditions of reflux in petrol and triethylamine (10), the corresponding thiazolidines $\mathbf{5 a - g}$ (Scheme 2) were obtained in good yield (Table 1) as stable oils and in approximately equal ratio of inseparable diastereomers. These products were readily purified by column chromatography, but could be used directly in the next step if desired. Coupling with monoethyl malonate using DCCl/ DMAP gave the product malonamides $\mathbf{6 a}-\mathbf{g}$ also in good yield (Table 1) and predominantly as the cis-isomer as shown by NOE analysis in several casesa (Figure 1). Cycli- $\mathbf{5}$ zation under standard conditions (reflux in presence of $\mathrm{KO}$-Bu) successfully gave the desired tetramates $\mathbf{7 a}-\mathbf{e}, \mathbf{g}$ in very good yield (Table 1) and as single diastereomers, with the ring stereochemistry again readily established by NOE analysisb (Figure 1). Noteworthy was that in these systems, reaction proceeded by initial epimerization of $\mathbf{6 a}$ -

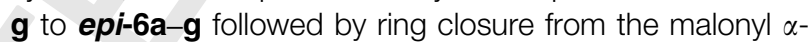
carbon onto the $\mathrm{C}(4)$ ester of the thiazolidine ring to give products $\mathbf{7 a - e , ~} \mathbf{g}$ (Scheme 3); this had been earlier found to be minor pathway in the serine and threonine systems leading to tetramates $\mathbf{3 a}, \mathbf{b}$ (Scheme 1) (11), and we attribute this difference both to the smaller aromatic substituent on the thiazolidine ring and to the larger sulphur atom, which makes the alternative $\mathrm{C}(4)$ enolate attack onto the terminal ethyl ester less sterically favourable. This is borne out by the fact that in the ring closure of thiazolidine $6(\mathrm{R}=t-\mathrm{Bu})$, product $7(\mathrm{R}=t-\mathrm{Bu})$ was obtained only as the minor product, with product $\mathbf{3 c}(\mathrm{X}=\mathrm{S}, \mathrm{R}=\mathrm{H})$ formed as the major one, as has been observed in the oxazolidine series (11). Cheminformatic analysis (Table 1) indicated that several of these compounds were indeed significantly more polar than the $t$-butyl analogue 7 ( $R=t-B u)$ $(\mathrm{Clog} \mathrm{P}=1.97, \mathrm{PSA}=63.7, \% \mathrm{PSA}=15.0)$, but all com- 6 pounds have very similar molecular volumes in the range of $235-280 \AA^{3}$. Of interest, however, is that although this approach could be used to access the malonamide derived from $p$-methoxybenzaldehyde, final ring closure was not successful, and $p$-hydroxybenzaldehyde failed in this sequence completely.

$\alpha$-Methyl serine could also be reacted with 5 -methylisoxazole-3-carbaldehyde to give oxazolidine 8 which, on condensation with malonate, gave cis- and trans-oxazolidines $\mathbf{9 a}$, b in 1:2 ratio (Scheme 4). Both oxazolidines were subjected to standard cyclization conditions but only trans oxazolidine $\mathbf{9 b}$ was successfully cyclized to give tetramate 10; the stereochemistry of this product was readily established by NOE analysis (Figure 1). Isomer 9a gave only the product from methyl ester hydrolysis. For the 
Table 1: Yields and cheminformatic data for products in Scheme 1

\begin{tabular}{|c|c|c|c|c|c|c|c|}
\hline \multirow[b]{2}{*}{ Compound (R) } & \multicolumn{3}{|l|}{ Yield (\%) } & \multicolumn{4}{|c|}{ Cheminformatic data ${ }^{a}$ for products 7} \\
\hline & 5 & 6 & 7 & ClogP & PSA & MSA & \%PSA \\
\hline a $\left(\mathrm{R}=\mathrm{C}_{4} \mathrm{H}_{3} \mathrm{O}\right)$ & $71(1: 1)$ & $74(3: 1)$ & 59 & 0.85 & 80.0 & 364 & 22.0 \\
\hline b $\left(\mathrm{R}=\mathrm{C}_{4} \mathrm{H}_{3} \mathrm{~S}\right)$ & $76(1: 1)$ & $61(1: 0)$ & 62 & 1.7 & 66.8 & 371 & 18.0 \\
\hline c $\left(\mathrm{R}=\mathrm{FC}_{6} \mathrm{H}_{4}\right)$ & $73(3: 2)$ & $68(4: 1)$ & 57 & 1.9 & 66.8 & 398 & 16.8 \\
\hline d $\left(\mathrm{R}=\mathrm{O}_{2} \mathrm{NC}_{6} \mathrm{H}_{4}\right)$ & $58(1: 1)$ & $72(5: 3)$ & 63 & 1.7 & 112.7 & 432 & 26.1 \\
\hline e $\left(\mathrm{R}=\mathrm{Cl}_{3} \mathrm{C}_{6} \mathrm{H}_{4}\right)$ & $73(1: 1)$ & $78(5: 2)$ & 68 & 3.6 & 66.8 & 438 & 15.2 \\
\hline $\mathbf{f}\left(\mathrm{R}=\mathrm{MeOC}_{6} \mathrm{H}_{4}\right)$ & $65(2: 1)$ & $61(2: 1)$ & - & - & - & - & - \\
\hline g $\left(\mathrm{R}=\mathrm{C}_{4} \mathrm{H}_{4} \mathrm{NO}\right)$ & $52(1: 3)$ & $64(5: 2)$ & 49 & 0.22 & 92.9 & 388 & 23.9 \\
\hline
\end{tabular}

aData compiled using Chemicalizec.

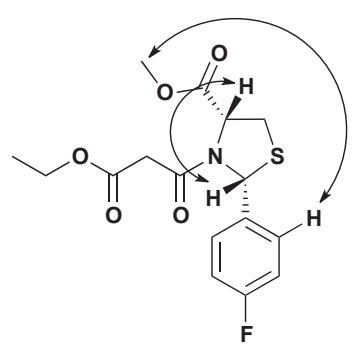

$5 c$

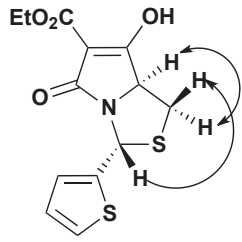

$7 b$<smiles>CCOC(=O)CC(=O)N1C2COC(=O)C1(c1ccc(OC)cc1)CSC2</smiles>

$5 f$

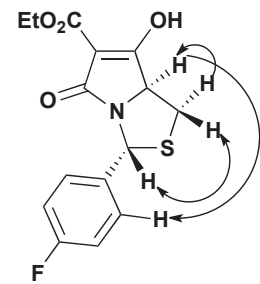

7c

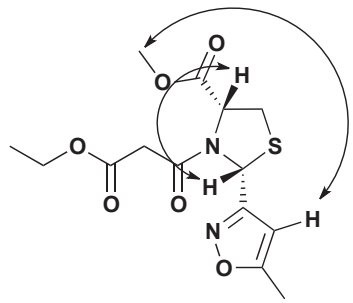

$5 \mathrm{~g}$

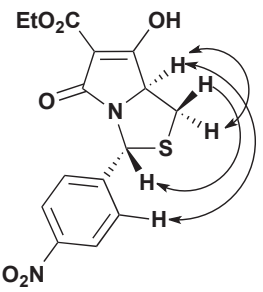

7d

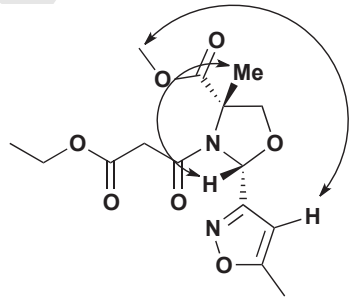

$9 a$

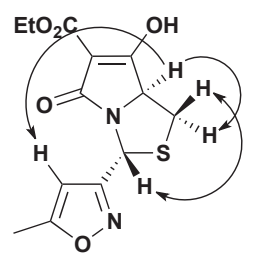

$7 g$

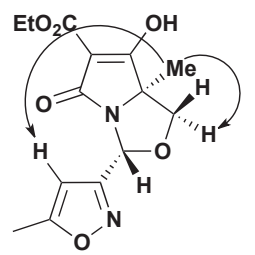

10

Figure 1: $x x x x x x x x x x x x x$.

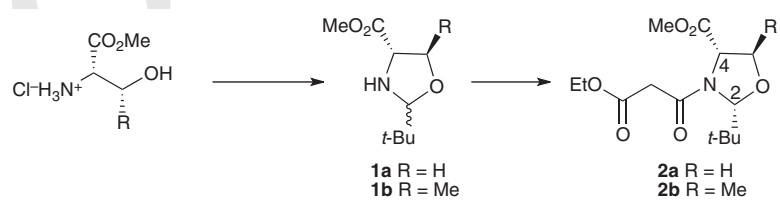

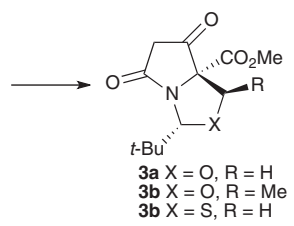

Scheme 1: $X x x x x x x x x x x x x$.

product 10, it was found that ClogP 0.02 and \%PSA 24.4 were consistent with a highly polar template, as might be expected.
Antibacterial biossayd of these compounds with Staphylococcus aureus and Escherichia coli showed that they were inactive for all compounds at concentrations of 2 and 


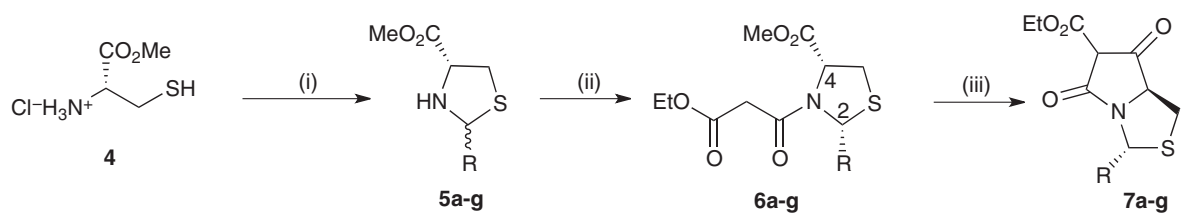

(i) RCHO, petrol (40/60), reflux, 16-20h; (ii) DCCl, DMAP, $\mathrm{EtO}_{2} \mathrm{CCH}_{2} \mathrm{CO}_{2} \mathrm{H}, \mathrm{DCM}$, 4h; (iii) KOt-Bu, THF<smiles>[Li][14c]1ccco1</smiles><smiles>C[Te](C)(C)c1cccs1</smiles>

b<smiles>Fc1ccccc1</smiles>

c<smiles>[3H][14c]1ccc([N+](=O)[O-])cc1</smiles>

d<smiles>Clc1cc(Cl)c(Cl)c(I)c1</smiles><smiles>COc1ccc(I)cc1</smiles>

f<smiles>Cc1cc(C)on1</smiles>

g

Scheme 2: $x x x x x x x x x x x x x$.<smiles>COC1(C)CS[C@@H]2C(=O)CC(=O)N21</smiles>

$3 c$
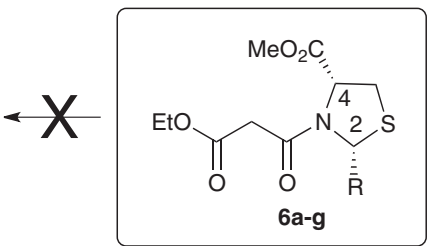
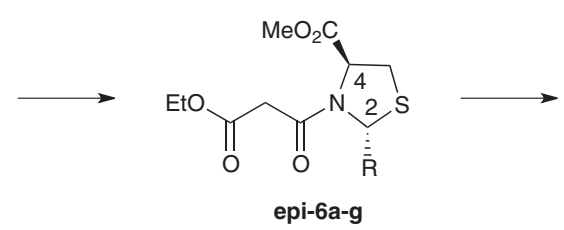<smiles>[R6][R6]C1SC[C@H]2C(=O)[C@H](C(=O)OCC)C(=O)N12</smiles>

Scheme 3: $X x x x x x x x x x x x x$.<smiles>CC(=O)C(C)([NH3+])CO</smiles><smiles>CCOc1cc(C)no1</smiles><smiles>CC(=O)C1(C)COC(c2cc(Cl)on2)N1</smiles>

8

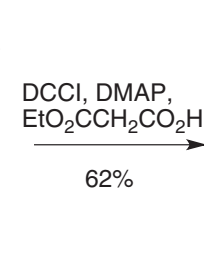

$9 b \mathrm{R}^{1}=\mathrm{Me}, \mathrm{R}^{2}=\mathrm{CO}_{2} \mathrm{Me}$

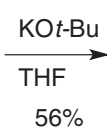<smiles>CCOC(=O)C1C(=O)N2[C@@H](c3cc(C)on3)OC[C@]2(C)C1=O</smiles>

10

Scheme 4: $X x x x x x x x x x x x x$.

$4 \mathrm{mg} / \mathrm{mL}$, with the exception of tetramate $7 \mathrm{c}$, which was found to be weakly active against $S$. aureus and E. coli, and compound $\mathbf{7 b}$, which was weakly active against E. coli, an outcome of interest because the two of them have very similar ClogP and \%PSA values. This general lack of bioactivity is consistent with our earlier results, which show that the intrinsic antibacterial activity of simple pyroglutamates $(12,13)$ and tetramates is low (14). On the other hand, introduction of appropriate side chain substituents returns antibacterial activity very effectively $(14,15)$, and suggests that these heterocyclic templates may provide useful skeletons for elaboration to biologically active systems.

Recently, there has been interest in the identification of heterocyclic systems (16) with increased molecular complexity suitable for 'escaping from flatland' in the process of drug discovery $(17,18)$. The systems reported herein offer non-planar but stereochemically well-defined skeletons, with several points of diversity, in as few as 3 synthetic steps from readily available starting materials and with favourable values of MW, PSA, numbers of rotatable bonds, $\mathrm{H}$-bond acceptors and $\mathrm{H}$-bond donors. Moreover, they have ample scope for ADMET optimization using the Lipinski parameters, for application in fragment-based drug design (19), in which there is significant current interest (20). They therefore offer promise for application as core systems for library generation in the drug discovery process, something we have already suggested for related oxazolidine systems (1).

\section{Acknowledgments}

We are particularly grateful for valuable input by Drs Phil Dudfield and John Lowther (Galapagos NV). 


\section{References}

1. Holloway C.A., Matthews C.J., Jeong Y.-C., Moloney M.G., Roberts C.F., Yaqoob M. (2011) Novel chiral skeletons for drug discovery: antibacterial tetramic acids. Chem Biol Drug Des;78:229-235.

2. Singh S.B., Zink D.L., Goetz M.A., Dombrowski A.W., Polishook J.D., Hazuda D.J. (1998) Equisetin and a novel opposite stereochemical homolog phomasetin, two fungal metabolites as inhibitors of HIV-1 integrase. Tetrahedron Lett;39:2243-2246.

3. Jung G., Hammes W., Ganzle M., Marquardt U., Holtzel A. (2000) Reutericyclin. EP 1116 715: EP 1116715.

4. Phillips J., Goetz M., Smith S., Zink D., Polishook J., Onishi R. et al. (2011) Discovery of kibdelomycin, a potent new class of bacterial type II topoisomerase inhibitor by chemical-genetic profiling in Staphylococ-

8 cus aureus. Chem Biol;18:955-965.

5. Tuske S., Sarafianos S.G., Wang X., Hudson B., Sineva E., Mukhopadhyay J. et al. (2005) Inhibition of bacterial RNA polymerase by streptolydigin: stabilization of a straight-bridge-helix active-center conformation. Cell;122:541-552.

6. Royles B.J.L. (1995) Naturally-occurring tetramic acids structure, isolation, and synthesis. Chem Rev;95: 1981-2001.

7. Andrews M.D., Brewster A.G., Crapnell K.M., Ibbett A.J., Jones T., Moloney M.G. et al. (1998) Regioselective Dieckmann cyclisations leading to enantiopure highly functionalised tetramic acid derivatives. J Chem

9 Soc Perkin Trans 1;????:223-235.

8. Anwar M., Cowley A.R., Moloney M.G. (2010) Novel chiral pyrrolidinone scaffolds derived from threonine with antibacterial activity. Tetrahedron: Asymmetry;21:1758-1770.

9. Seebach D., Sting A.R., Hoffmann M. (1996) Selfregeneration of stereocenters (SRS) - applications, limitations, and abandonment of a synthetic principle. Angew Chem Int Ed Engl;35:2708-2748.

10. Seebach D., Aebi J.D. (1984) $\alpha$-Alkylation of serine with self-reproduction of the center of chirality. Tetrahedron Lett;25:2545-2548.

11. Jeong Y.-C., Anwar M., Nguyen T.M., Tan B.S.W., Chai C.L.L., Moloney M.G. (2011) Control of chemoselectivity in Dieckmann ring closures leading to tetramic acids. Org Biomol Chem;9:6663-6669.

12. Chandan N., Moloney M.G. (2008)Rapid synthesis of trisubstituted pyroglutamate derivatives. Org Biomol Chem;6:3664-3666.

13. Hill T., Kocis P., Moloney M.G. (2006) Stereocontrolled spirocyclic bislactams derived from pyroglutamic acid. Tetrahedron Lett;47:1461-1463.

14. Jeong Y.-C., Moloney M.G. (2009) Tetramic acids as bioactive templates: synthesis, tautomeric and antibac-

10 terial behaviour. Synlett;???:2487-2491

15. Jeong Y.-C., Anwar M., Moloney M.G., Bikadi Z., Hazai E. (2013) Natural product inspired antibacterial tetramic acid libraries with dual enzyme target activity. Chem Sci;???:????. DOI: 10.1039/C2SC21713A.
16. Pitt W.R., Parry D.M., Perry B.G., Groom C.R. (2009) Heteroaromatic rings of the future. $J$ Med Chem;52:2952-2963.

17. Lovering F., Bikker J., Humblet C. (2009)Escape from flatland: increasing saturation as an approach to improving clinical success. J Med Chem;52:6752-6756.

18. Ritchie T.J., MacDonald S.J.F. (2009) The impact of aromatic ring count on compound developability - are too many aromatic rings a liability in drug design? Drug Discov Today; 14:1011-1020.

19. Hajduk P.J. (2006) Fragment-based drug design: how big is too big? J Med Chem;49:6972-6976.

20. Congreve M., Chessari G., Tisi D., Woodhead A.J. (2008) Recent developments in fragment-based drug discovery. J Med Chem;51:3661-3680.

21. Smith B., Warren S.C., Newton G.G.F., Abraham E.P. (1967) Biosynthesis of penicillin N and cephalosporin C - antibiotic production and other features of metabolism of A Cephalosporium Sp. Biochem J;103:877-890.

22. Baldwin J.E., Coates J.B., Halpern J., Moloney M.G., Pratt A.J. (1989) Photoaffinity labelling of isopenicillin N synthetase using laser flash photolysis. Biochem J;261:197-204.

23. Baldwin J.E., Pratt A.J., Moloney M.G. (1987) The synthesis of aryl substituted analogues of phenoxyacetyl-L-cysteinyl-D-valine and phenylacetyl-L-cysteinyl-Dvaline. Application to the photoaffinity labelling of isopenicillin N synthetase. Tetrahedron;43:2565-2575.

Notes

${ }^{a}$ General acylation method: To a stirred solution of thiazolidine $\mathbf{5 a - g}$ and dicyclohexylcarbodiimide (DCCl) and DMAP in DCM $(20 \mathrm{~mL})$ at $0^{\circ} \mathrm{C}$ was added a solution of ethyl hydrogen malonate in DCM $(3 \mathrm{~mL})$. The mixture was stirred at $0^{\circ} \mathrm{C}$ for $15 \mathrm{~min}$ then at room temperature for $4-5 \mathrm{~h}$. The reaction mixture was filtered to remove dicyclohexyl urea, the residue was washed with $\operatorname{DCM}(3 \times 15 \mathrm{~mL})$, and the combined filtrates were evaporated in vacuo to give products $\mathbf{6 a - g}$.

${ }^{\mathrm{b}}$ General cyclization method: To a solution of thiazolidine 6a-g $(1.0 \mathrm{mmol})$ in dry THF $(15 \mathrm{~mL})$ was added $\mathrm{KO}^{\mathrm{t}} \mathrm{Bu}$ $(1.05 \mathrm{mmol})$ and solution was heated at reflux for $3 \mathrm{~h}$, cooled to room temperature and partitioned between ether $(15 \mathrm{~mL})$ and water $(2 \times 15 \mathrm{~mL})$. The aqueous layer was acidified with $2 \mathrm{M} \mathrm{HCl}$ and extracted with ethyl acetate $(3 \times 15 \mathrm{~mL})$. The combined ethyl acetate extracts were washed with brine, dried over MgSO4 and evaporated in vacuo. The residue was purified by flash column chromatography (EtOAc:MeOH; 5:1) to give the products $\mathbf{7 a - e , ~} \mathbf{g}$. ${ }^{\circ}$ Chemicalize.org was used for drawing, displaying and characterizing chemical structures, substructures and reactions (http://www.chemaxon.com).

a Bioassay of products: (21-23) Microbiological assays were performed by the hole-plate method with the test organism Staphylococcus aureus N.C.T.C. 6571 or E. coli X580. Solutions $(100 \mu \mathrm{L})$ of the compounds to be tested (4 mg/mL) were loaded into wells in bioassay plates, and 


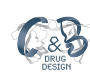

incubated overnight at $37^{\circ} \mathrm{C}$. The diameters of the resultant inhibition zones were measured $( \pm 1 \mathrm{~mm})$, and relative potency estimated by reference to standards prepared with cephalosporin C; this is expressed as zone diameter per $\mathrm{M}$, of the analyte relative to cephalosporin C standard.

\section{Supporting Information}

Additional Supporting Information may be found in the online version of this article:

Appendix S2. $X x x x x x x x x x x$. 


\section{Graphical Abstract}

The contents of this page will be used as part of the graphical abstract of html only. It will not be published as part of main.

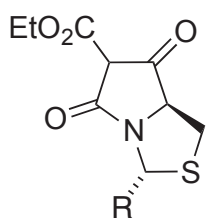

2 Chiral tetramates are readily prepared and may be used to generate libraries suitable for drug development. 


\section{Author Query Form}

Journal: $\quad$ CBDD

Article: $\quad 12110$

Dear Author,

During the copy-editing of your paper, the following queries arose. Please respond to these by marking up your proofs with the necessary changes/additions. Please write your answers on the query sheet if there is insufficient space on the page proofs. Please write clearly and follow the conventions shown on the attached corrections sheet. If returning the proof by fax do not write too close to the paper's edge. Please remember that illegible mark-ups may delay publication.

Many thanks for your assistance.

\begin{tabular}{|c|c|c|}
\hline Query reference & Query & Remarks \\
\hline 1 & $\begin{array}{l}\text { AUTHOR: A running head short title was not supplied; please check if this } \\
\text { one is suitable and, if not, please supply a short title of up to } 40 \text { charac- } \\
\text { ters that can be used instead. }\end{array}$ & $\equiv$ \\
\hline 2 & AUTHOR: Please confirm that graphical abstract is fine for publication & $\equiv$ \\
\hline 3 & WILEY-BLACKWELL: Please supply date of revision. & $\equiv$ \\
\hline 4 & $\begin{array}{l}\text { AUTHOR: In the sentence "We have been... core tetramate unit", the term } \\
\text { "streptolodygin" has been changed to "Streptolydigin". Please check the } \\
\text { spelling of the term. }\end{array}$ & $\overline{\bar{E}}$ \\
\hline 5 & AUTHOR: Please define NOE. & $\equiv$ \\
\hline 6 & AUTHOR: Please define PSA. & $\equiv$ \\
\hline 7 & $\begin{array}{l}\text { AUTHOR: Please provide a suitable legends for Figure } 1 \text { and Schemes } 1- \\
4 .\end{array}$ & $\equiv$ \\
\hline 8 & $\begin{array}{l}\text { AUTHOR: If there are fewer than } 16 \text { authors for References, please supply } \\
\text { all of their names. If there are } 16 \text { or more authors, please supply the first } 7 \\
\text { author names then et al. Please check and update all such references } \\
\text { found in the list. }\end{array}$ & \\
\hline 9 & AUTHOR: Please provide volume number for reference [7]. & $\equiv$ \\
\hline 10 & AUTHOR: Please provide the volume number for reference [14]. & $\equiv$ \\
\hline 11 & $\begin{array}{l}\text { AUTHOR: Please provide the volume number, page range for reference } \\
\text { [15]. }\end{array}$ & \\
\hline 12 & AUTHOR: Please provide a suitable legends for Appendices S1 and S2. & $\equiv$ \\
\hline 13 & $\begin{array}{l}\text { AUTHOR: As per journal style website references and general statements } \\
\text { are not allowed in reference list. Hence they moved into notes section and } \\
\text { rest of references are renumbered. Please check. }\end{array}$ & $\equiv$ \\
\hline 14 & $\begin{array}{l}\text { AUTHOR: Please check this website address and confirm that it is correct. } \\
\text { (Please note that it is the responsibility of the author(s) to ensure that all } \\
\text { URLs given in this article are correct and useable.) }\end{array}$ & $\equiv$ \\
\hline
\end{tabular}


Required software to e-Annotate PDFs: Adobe Acrobat Professional or Adobe Reader (version 7.0 or above). (Note that this document uses screenshots from Adobe Reader $\mathbf{X}$ )

The latest version of Acrobat Reader can be downloaded for free at: http://get.adobe.com/uk/readerl

Once you have Acrobat Reader open on your computer, click on the Comment tab at the right of the toolbar:

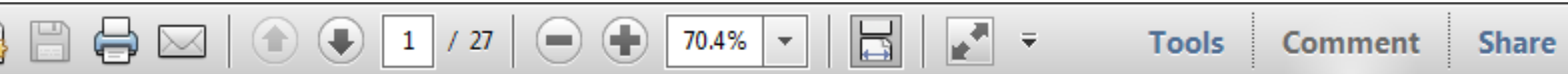

This will open up a panel down the right side of the document. The majority of tools you will use for annotating your proof will be in the Annotations section, pictured opposite. We've picked out some of these tools below:

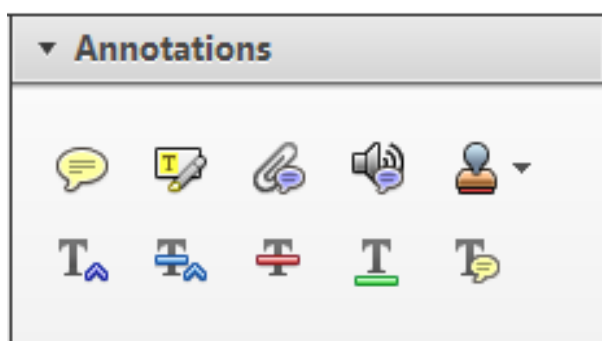

1. Replace (Ins) Tool - for replacing text.

Strikes a line through text and opens up a text box where replacement text can be entered.

How to use it

- Highlight a word or sentence

- Click on the Replace (Ins) icon in the Annotations section.

- Type the replacement text into the blue box that appears.

Idard tramework for the analysis of $\mathrm{m}$ icy-Nevertheless, it also led to exog،

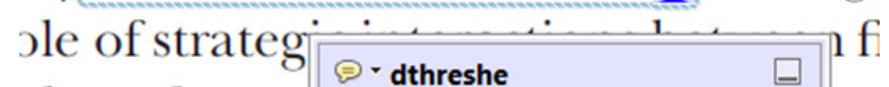
aber of comp 08/06/2011 15:58:17 is that the $\mathrm{s} 1 \overline{\text {, which led }}$ of nain compo: be level, are exc nc

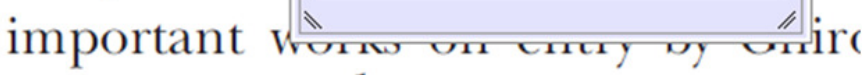
M henceforth) ${ }^{1}$ we snen the "hlark $\mathrm{h}$

3. Add note to text Tool - for highlighting a section to be changed to bold or italic.

Th Highlights text in yellow and opens up a text box where comments can be entered.

\section{How to use it}

- Highlight the relevant section of text.

- Click on the Add note to text icon in the Annotations section.

- Type instruction on what should be changed regarding the text into the yellow box that appears

namic responses of mark ups ent with the VAR evidence

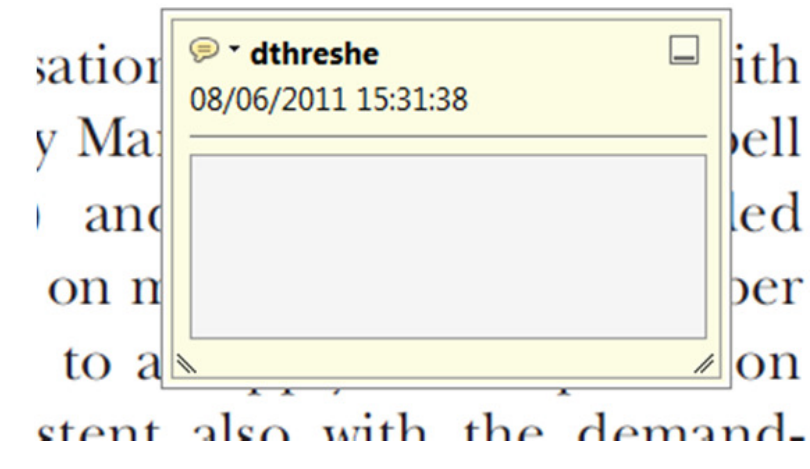

2. Strikethrough (Del) Tool - for deleting text.

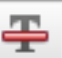

Strikes a red line through text that is to be deleted.

How to use it

- Highlight a word or sentence.

- Click on the Strikethrough (Del) icon in the Annotations section.

there is no room tor extra prohts al s ups are zero and the number of ret) values are not determined by Blanchard and Kiyotaki (1987), sfect competition in general equilil ts of aggregate demand and supply lassical framework assuming mono sen on evorenous nimher of firms

4. Add sticky note Tool - for making notes at specific points in the text.

Marks a point in the proof where a comment needs to be highlighted.

How to use it

- Click on the Add sticky note icon in the Annotations section.

- Click at the point in the proof where the comment should be inserted.

- Type the comment into the yellow box that appears.

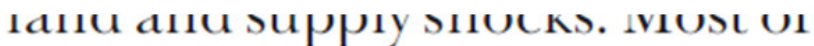

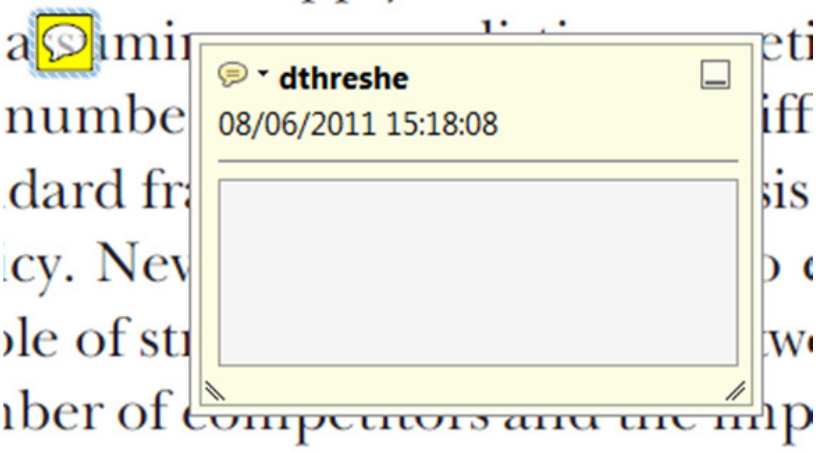

is that the structure of the sects. 
5. Attach File Tool - for inserting large amounts of text or replacement figures.

Inserts an icon linking to the attached file in the appropriate pace in the text.

How to use it

- Click on the Attach File icon in the Annotations section.

- Click on the proof to where you'd like the attached file to be linked.

- Select the file to be attached from your computer or network.

- Select the colour and type of icon that will appear in the proof. Click OK.

E N D

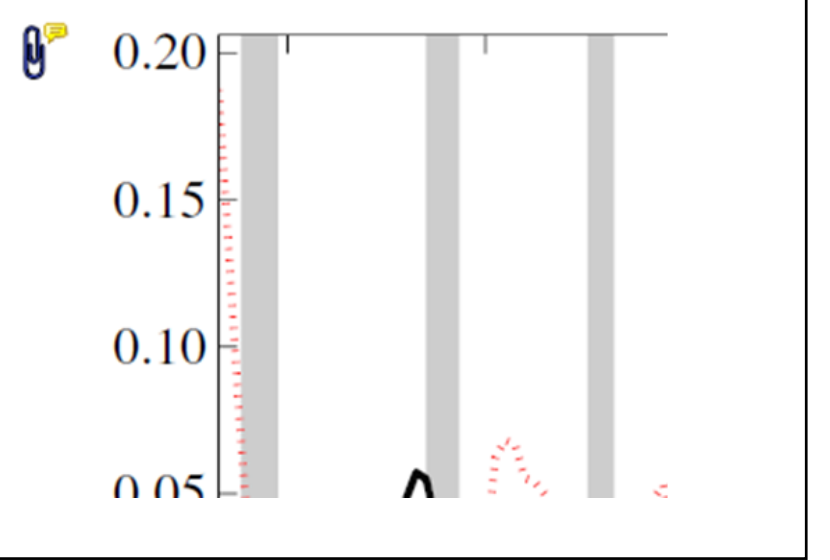

6. Add stamp Tool - for approving a proof if no corrections are required.

- Inserts a selected stamp onto an appropriate place in the proof

\section{How to use it}

- Click on the Add stamp icon in the Annotations section.

- Select the stamp you want to use. (The Approved stamp is usually available directly in the menu that appears).

- Click on the proof where you'd like the stamp to appear. (Where a proof is to be approved as it is, this would normally be on the first page).

of the Dusiness cycie, starting with the on perfect competition, constant ret

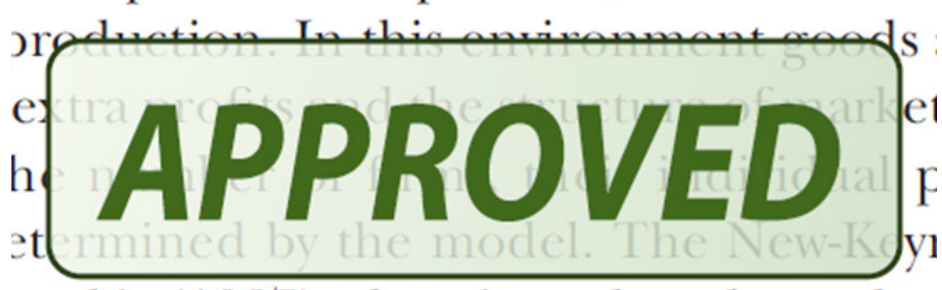
otaki (1987), has introduced produc general equilibrium models with nomin:

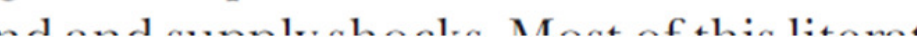

- Drawing Markups

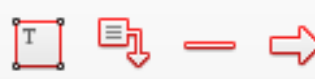

$0 \square \sqrt{ } \rightarrow 0$

\section{How to use it}

- Click on one of the shapes in the Drawing Markups section.

- Click on the proof at the relevant point and draw the selected shape with the cursor.

- To add a comment to the drawn shape, move the cursor over the shape until an arrowhead appears.

- Double click on the shape and type any text in the red box that appears.
7. Drawing Markups Tools - for drawing shapes, lines and freeform annotations on proofs and commenting on these marks.

Allows shapes, lines and freeform annotations to be drawn on proofs and for comment to be made on these marks.

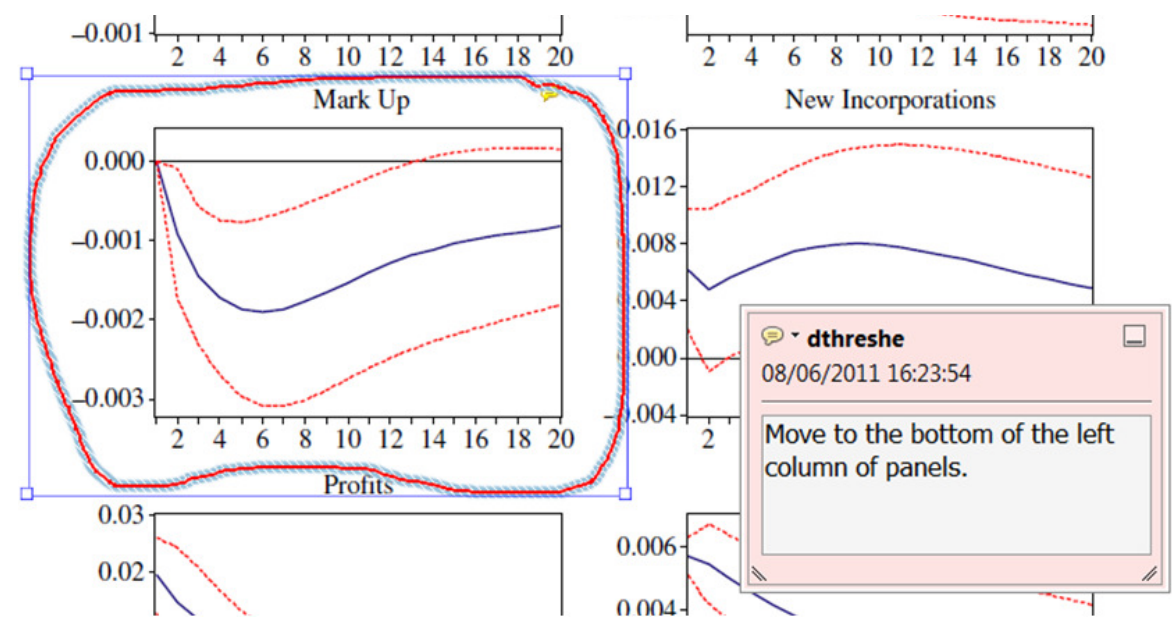

For further information on how to annotate proofs, click on the Help menu to reveal a list of further options:

\begin{tabular}{|l|l|l|l|l|l|l|}
\hline File ecoj_2384_CrxRev2_EV_19-Jul-10.pdf - Adobe Reader & Edit View Window \\
\hline
\end{tabular}

